\title{
Entre cruzadas y mesianismos. Alfredo Stroessner, Francisco Franco y la legitimación histórica
}

Tomás Sansón Corbo*

\section{Resumen}

La utilización de la Historia para convalidar gobiernos autoritarios es un asunto que ha tenido múltiples abordajes. No son comunes, en cambio, investigaciones sobre los relatos de carácter pretérito elaborados por los propios autócratas. El objetivo de este artículo es "escuchar" la "voz de los dictadores" para revisar sus interpretaciones históricas e identificar las estrategias utilizadas para hacerlas funcionales a sus intereses. Se propone un análisis comparado de textos de Francisco Franco (España, 1939-1975) y Alfredo Stroessner (Paraguay, 1954-1989) referidos a la h(H)istoria. Se trata de dos casos razonablemente parangonables cuyo examen permite establecer ciertas regularidades.

Palabras clave: Usos de la Historia - historiografía y dictaduras - Alfredo Stroessner y Francisco Franco.

\section{Summary}

The use of History to validate authoritarian governments is an issue that has been approached in many ways. On the other hand, research on the narratives of a past character elaborated by the autocrats themselves is not common. The aim of this article is to "listen" to the "voice of the dictators" in order to review their historical interpretations and identify the strategies used to make them functional to their interests. A comparative analysis of texts by Francisco Franco (Spain, 1939-1975) and Alfredo Stroessner (Paraguay, 1954-1989) referring to $\mathrm{h}(\mathrm{H})$ istory is proposed. These are two reasonably comparable cases whose examination allows establishing certain regularities.

\footnotetext{
* Universidad de la República. E mail: slbt@hotmail.com
} 
Keywords: Uses of History - Historiography and Dictatorships - Alfredo Stroessner and Francisco Franco.

\section{Introducción}

La práctica de la Historia en contextos políticos autoritarios se encuentra condicionada por mecanismos de control implementados por los agentes del poder fáctico. Producción de conocimiento; formación de investigadores y de docentes; elaboración, edición y distribución de textos (académicos y didácticos); administración de efemérides, nomenclátor y celebraciones patrióticas; planes y programas de "historia nacional" (en todos los niveles educativos), son actividades intervenidas y normalizadas. Un elenco de celosos gendarmes del pensamiento se encargan de definir los mitemas y referentes pretéritos articuladores del imaginario colectivo. Implementan los mecanismos de regulación necesarios a efectos de asegurar la socialización (imposición) de los mismos con propósitos legitimadores.

El discurso histórico oficial adquiere dimensión canónica. La dinámica del campo disciplinario se ralentiza en virtud de restricciones heterónomas (ideológicas y funcionales). Las disidencias interpretativas pueden considerarse potencialmente subversivas.

Quienes detentan el poder político pretenden ejercer el monopolio de la gestión de los estudios sobre el pasado. Promueven a los autores y centros académicos afines a su perspectiva epistemológica e ideológica. Se trata de un conjunto de intelectualesfuncionarios que, de manera heterónoma, establecen las reglas del juego y condicionan las relaciones dentro del campo inhibiendo la competencia entre los agentes. ${ }^{1}$

Los intelectuales encuadrados en la "legalidad epistemológica" del régimen son responsables de la elaboración de los relatos oficiales. Se convierten en los principales manipuladores de la Historia y contribuyen a legitimar a los poderes de turno. Recibirán a cambio privilegios funcionales, simbólicos y materiales (cargos, financiamiento, prestigio).

1 Los campos historiográficos se estructuran en base a relaciones de competencia y complementariedad entre sus agentes (los historiadores). El acceso, acción, permanencia y exclusión están normalizados por reglas definidas por los propios agentes, de acuerdo a su posición (dominadores o dominados) y "peso funcional" (autoridad, poder) (Bourdieu, 2002). 
Los dictadores no solo son actores protagónicos de la historia, en ocasiones también son autores de la misma. Algunos registran, en sendos textos (elaborados por ellos o realizados por escribas fieles), sus interpretaciones sobre el devenir y lo relacionan con el presente. Se trata, en general, de discursos, artículos periodísticos, proclamas y, ocasionalmente, ensayos específicamente históricos en los que exponen sus convicciones/creencias y los consensos definidos por los gendarmes del pensamiento. En esos documentos se condensan los mitemas referenciales que definen el ser de la nación, el sentido de la misma, el decálogo del patriota y las profecías mesiánicas auto-realizadas.

Los textos de los autócratas adquieren el carácter de sumas canónicas en las que se definen ciertas "verdades" de carácter indiscutible. Su estudio permite dilucidar, desde una perspectiva privilegiada, la constelación de imágenes y axiomas de carácter pretérito que sostienen al régimen. Propongo, por las razones expuestas, realizar un análisis sobre un conjunto de textos de Francisco Franco y Alfredo Stroessner con el propósito de conocer, sin interpósitas valoraciones, sus interpretaciones históricas. Se trata de dos casos razonablemente comparables cuyo examen permite establecer, a partir de sus singularidades y semejanzas, ciertas regularidades relacionadas con los usos del pasado por parte de los dictadores.

Se han publicado diversas investigaciones sobre la producción de conocimiento histórico durante los gobiernos de Stroessner y de Franco. En relación al caso paraguayo se destacan los estudios de Liliana Brezzo ${ }^{2}$, Lorena Soler ${ }^{3}$ y Luc Capdevila ${ }^{4}$; sobre la situación en España son fundamentales los trabajos de Gonzalo Pasamar ${ }^{5}$, Ignacio Peiró ${ }^{6}$, Gustavo Alares ${ }^{7}$, José Álvarez Junco y Gregorio de la Fuente $^{8}$, entre otros. Pero, prácticamente, no existen pesquisas específicas sobre los textos de carácter histórico elaborados (o firmados) por los propios autócratas; los únicos autores que se acercaron tangencialmente al asunto fueron Luc Capdevila -

2 Brezzo, 2014, 2016, 2017.

3 Soler, 2007.

4 Capdevila, 2008, 2010.

5 Pasamar, 2002; Pasamar, Peiró, 2002.

6 Peiró, 2013.

7 Alares, 2017.

8 Álvarez Junco \& de la Fuente, 2017. 
quien realizó una interesante referencia a una obra de Stroessner ${ }^{9}$ - y Josep Fontana - comentando ciertos tópicos que aparecen reiteradamente en discursos y alocuciones de Franco $^{10}-$.

\section{Los "autores"}

Francisco Franco y Alfredo Stroessner presentan un conjunto de rasgos comunes que invitan al análisis comparativo de sus personas y gobiernos. Comparten el dudoso mérito de haber protagonizado dos de las dictaduras más longevas del mundo occidental, gobernaron sus países por más de tres décadas (de 1939 a 1975 y de 1954 a 1989 respectivamente). Participaron en importantes conflictos internacionales (Franco en la Guerra de Marruecos y Stroessner en la del Chaco), que les permitieron acumular experiencia de mando y ascender rápidamente en el escalafón militar. Se involucraron en guerras civiles que tuvieron trágicas consecuencias para sus países (el ferrolano en el conflicto de 1936 a 1939 y el germano-guaraní en la contienda de 1947) y se convirtieron en referentes de las facciones vencedoras (el partido Colorado en el caso del paraguayo, el "Movimiento Nacional" en el del español).

Cuando ocupaban puestos militares destacados, sus países atravesaban situaciones de crisis. España en 1939 y Paraguay en 1954 ofrecían escenarios favorables para la emergencia de mesianismos que aseguraran "paz y orden".

Ambas naciones habían sufrido derrotas militares terribles ${ }^{11}$ que los afectaron en múltiples sentidos. Debieron, entre otros aspectos, replantearse su "lugar" en el concierto internacional, el "sentido" de sus historias y, por ende, la escritura de las mismas. En esos contextos se formaron nuestros protagonistas.

Alfredo Stroessner Matiauda nació en la ciudad de Encarnación el 3 de noviembre de 1912. Descendía del inmigrante alemán Hugo Stroessner y de la criolla Heriberta Matiauda. A los 17 años ingresó a la Academia Militar en el arma de Artillería.

9 Capdevila, 2010.

10 Fontana, 1999.

11 España había perdido Cuba (1898) y Paraguay fue derrotado en la Guerra de la Triple Alianza (entre 1864 y 1870). 
Realizó varios cursos de perfeccionamiento en su país y en el exterior. Combatió en la Guerra del Chaco y en la guerra civil de 1947. En 1951 fue nombrado General de División y se afilió al Partido Colorado. Participó del golpe de Estado del 4 de mayo de 1954 que derrocó al presidente Federico Chaves. Procuró legitimar jurídicamente su gobierno convocando a unas elecciones, efectuadas en agosto del mismo año, en las que fue candidato único del Partido Colorado.

Inauguró entonces la práctica de realizar actos comiciales cada cinco años que daban una fachada de legalidad a su gobierno. Se trataba de instancias electorales, organizadas en el contexto del Estado de Sitio permanente (que se levantaba días antes de los comicios), de las que se abstenían de participar la mayoría de los partidos de oposición. En la década de 1960 algunos sectores colaboracionistas de la oposición - fundamentalmente del Partido Liberal y del Febrerista - aceptaron presentar candidatos a cambio de prebendas.

El gobierno de Stroessner fue recibido con moderada expectativa por sectores sociales y políticos que estaban cansados de la inestabilidad imperante. Entre 1956 y 1962 debió enfrentar algunas situaciones que pusieron en riesgo su continuidad (intentos de golpes de Estado, huelgas sindicales y estudiantiles, levantamientos guerrilleros del Movimiento 14 de Mayo y del FULNA). La fase de apogeo del régimen se efectivizó entre 1966 y 1980, estuvo caracterizada por un importante despegue económico gracias a la realización de grandes obras de infraestructura (represa de Itaipú, ciudad Presidente Stroessner). Durante la década de 1980 se produjo el declive del régimen, debido a la acción confluyente de diversos factores internos $^{12}$ y externos ${ }^{13}$, que culminó en la noche del 2 y 3 de febrero de 1989 cuando el general Andrés Rodríguez lideró un golpe que derrocó al viejo autócrata. ${ }^{14} \mathrm{El}$ encarnaceno marchó al exilio en Brasil donde permaneció hasta su muerte el 16 de agosto de 2006.

Francisco Franco Bahamonde nació en El Ferrol, Galicia, el 4 de diciembre de 1892. Fue hijo de Nicolás Franco y Pilar Bahamonde. Ingresó, en 1907 en la Academia de Infantería de Toledo. Egresó de la misma en 1910 con el grado de segundo teniente.

12 Cese de la bonanza económica y división del Partido Colorado (en el seno del cual surgieron tendencias que reclamaban un cambio en el gobierno).

13 La política en favor de los derechos humanos del gobierno de Jimmy Carter en Estados Unidos. 14 Cf. Paredes, 2011: 306-310. 
Su bautismo de fuego se produjo en Marruecos el 19 de marzo de 1912. Durante la guerra africana se destacó por su valor y capacidad de mando. Se integró a la Legión Española a solicitud de su creador, José Millán Astray. En 1926 fue ascendido a general de brigada debido, fundamentalmente, al destacado rol que tuvo en las operaciones combinadas franco-españolas en el marco del desembarco de Alhucemas. Tenía apenas treinta y tres años.

Monárquico de tradición, anticomunista y católico ferviente no se sintió muy cómodo con el advenimiento de la República en 1931. Las autoridades del nuevo gobierno nunca confiaron en él. Luego del triunfo del Frente Popular, en febrero de 1936, fue destinado a la comandancia militar de Canarias. Pertenecía al grupo de militares “africanistas” que desencadenó, en julio de 1936, la Guerra Civil Española. Fue designado, por parte de los generales conjurados, comandante supremo del “Alzamiento Nacional” (Burgos, 1 de octubre de 1936).

En 1939, luego del triunfo sobre las fuerzas de la República, instauró un gobierno autoritario que se extendió hasta 1975 y pasó por tres períodos: "1. La fase pseudofascista y potencialmente imperialista de 1936-1945. 2. El periodo del nacionalcatolicismo corporativo entre 1945-1959. 3. El periodo llamado de desarrollismo tecnocrático, poco a poco evolucionando hacia un autoritarismo burocrático de 1959-1975". ${ }^{15}$ Su permanencia en el poder se explica por el férreo despotismo con que actuó hacia el interior de España y por el pragmatismo y habilidad que demostró hacia el exterior. Murió en Madrid el 20 de noviembre de 1975.

Es interesante indicar que en 1973 se produjo un "encuentro fraternal" entre ambos autócratas. Stroessner visitó Madrid, entre el 16 y el 20 de julio, acompañado por su esposa y una comitiva oficial. Durante esas jornadas fue agasajado por diversas corporaciones, participó en actos protocolares y se entrevistó con Franco. El encarnaceno tenía sesenta años, hacía diecinueve que gobernaba Paraguay. El ferrolano, por su parte, con ochenta años, gobernaba desde 1939. Con motivo de la entrega de las llaves de Madrid, el alcalde Jesús Suevos expresó que Stroessner era

la máxima representación de un pueblo que coloca el heroísmo por encima de todas sus cualidades y virtudes. El valor de las gentes paraguayas es proverbial

15 Pastor, 2017. 
en toda América y en España ha suscitado siempre admiración y orgullo. $V$ uestro pueblo luchó con admirable arrojo contra fuerzas muy superiores en número hasta casi el exterminio. Pero su gallardía no fue inútil, pues babéis mantenido intacto el tesoro de vuestra independencia nacional. El pueblo de Madrid, que también supo luchar y morir por la independencia de España, os puede comprender muy bien. Porque nos une a paraguayos y españoles la suprema hermandad del patriotismo bistórico ${ }^{16}$

El "patriotismo histórico" y el "heroísmo" fueron, precisamente, algunas de las notas dominantes en la ideología y en la mentalidad de los regímenes autoritarios de Madrid y Asunción que los autócratas utilizarían con fines convalidadores.

\section{Los generales y la $\mathrm{h}(\mathrm{H})$ istoria}

\section{Los textos}

La apropiación coercitiva de la soberanía popular supone un necesario secuestro de la historia. Se trata de una constante, que trasciende tiempos y espacios. Se efectiviza a través de medidas que, invariablemente, afectan la práctica profesional de investigadores y centros académicos (censura, destituciones, control de la elaboración de planes, programas y manuales de enseñanza).

El uso del pasado es garantizado por los "historiadores leales". Éstos pueden ser fuente y/o receptáculo de las convicciones pretéritas que sustentan al régimen y que se difunden a través de todos los recursos disponibles por parte del Estado. En los casos de las dictaduras de Paraguay y España, los propios autócratas fungieron como agentes de auto-convalidación. Lo hicieron a través de una serie de textos muy variopintos que podrían calificarse, en general, como "ensayísticos" debido a su carácter interpretativo y propositivo. Se trata de proclamas, discursos, artículos y opúsculos en los que se interpreta el pasado en función del presente. Plantean un conjunto de "verdades" articuladas sin base documental y de manera artificiosa. Tienen carácter performativo pues definen los modelos del "buen paraguayo" y del "buen español" en base a ejemplos personalizados, claros e indiscutibles.

Franco y Stroessner no eran escritores ni intelectuales, pero no vacilaron en apropiarse de un conjunto de ideas planteadas por sus colaboradores y que formaban

16 Suevos, 1973: 20. 
parte de las lecturas que habían forjado su pensamiento. Las canalizaron a través de textos que serían ampliamente difundidos por la propaganda oficial. Algunos de esos productos presentan proposiciones curiosas y originales que reflejan las "creencias" dominantes en la cultura histórica del grupo político de referencia (Partido Colorado o Movimiento Nacional) y del background del autor.

El ferrolano tenía gran afición por la lectura y la escritura. En su juventud escribió artículos de carácter militar para la Revista de Tropas Coloniales (que llegó a dirigir). Dejó testimonio de sus experiencia militares en África a comienzos de la década de 1920 en Marruecos: diario de una bandera (1922, prologada por Millán-Astray). En las décadas de 1940 y 1950 publicó artículos políticos e históricos en la prensa del régimen. Elaboró por sí mismo muchos de los discursos y proclamas pronunciados durante su mandato. Fue autor (con el seudónimo de "Jaime de Andrade") de la novela histórica Raza (1942), que fungiría como guión para la película homónima dirigida por José Luis Sáenz de Heredia.

Se han realizado diversos estudios sobre los textos atribuidos a Franco con el propósito de conocer su ideología y doctrina política. El ferrolano sintetizaba en sus escritos aportes de otros agentes del Movimiento Nacional como Emilio Mola, José Millán Astray e Isidro Gomá; en ocasiones colaboraban en el proceso de escritura algunos miembros de su gabinete como Luis Carrero Blanco. ${ }^{17}$ Es posible que el intelectual falangista Ernesto Giménez Caballero haya sugerido ideas para los artículos sobre la masonería que Franco posteriormente desarrollaría con la colaboración de Carrero Blanco. ${ }^{18}$

El dictador guaraní, por su parte, fue menos prolífico pero más preciso que su colega ibérico. Las referencias al pasado estaban presentes de manera permanente - e incluso saturante - en sus alocuciones y textos. Luc Capdevila sostiene que el "general no escribia sus discursos ni los textos que firmaba", sus "consejeros lo bacian por él"; de todos modos, "se los apropiaba como conocedor crítico de las cosas del pasado". ${ }^{19}$

Diversos indicios sugieren que "las plumas detrás de la firma" de Stroessner corresponderían al legendario autor nacionalista Juan O'Leary - en la etapa de

17 Eiroa, 2012: 72.

18 Cf. Sánchez \& Lumbreras, 2016: 46.

19 Capdevila, 2010: 230. 
afirmación y consolidación del régimen $-\mathrm{y}$ a los intelectuales colorados Luis G. Benítez, Sindulfo Pérez Moreno y Carlos Meo - en la fase de apogeo -. Un análisis sinóptico de los textos firmados por Stroessner por un lado, con las obras de Benítez - didascálicas y hagiográfico-apologéticas ${ }^{20}$-, Pérez y $\mathrm{Meo}^{21}$ por otro, revelan varias similitudes (en ciertos tópicos identificados como arquetipos del devenir del "pueblo mártir" y en las tramas argumentales utilizadas para manipular el pasado en orden a legitimar el gobierno del "hombre fuerte" que orientaba "los destinos de la Patria").

Stroessner se formó en el babitus $^{22}$ de nacionalismo belicista y excluyente fogoneado por O'Leary desde comienzos del siglo XX. Compartía los postulados del "revisionismo" paraguayo y los transformó en ideología de su gobierno. Por estas razones, aunque no haya sido el autor original de los textos que se le atribuyen, se apropió de ellos e introdujo aportes personales.

Para el conocimiento del pensamiento histórico de los autócratas se escogió un conjunto de textos, considerados representativos, que se examinan con el propósito de identificar sus ideas fundamentales en torno a la historia y a la instrumentalización de la misma. En el caso Franco se analizarán discursos y alocuciones pronunciados después de 1936 y el libro Masonería en el que, bajo el seudónimo de Jakim Boor, compiló una serie de artículos publicados en el periódico falangista Arriba; el ferrolano tenía un carácter muy reservado y pocas personas sabían que él era el autor que se ocultaba bajo estos seudónimos; su hija Carmen confesó que el padre " $n o$ hablaba de eso", escribía los textos "pero yo creo que prefería que no se supiera que era él". ${ }^{23} \mathrm{De}$ Stroessner se abordarán algunos discursos pronunciados durante su mandato y, especialmente, el capítulo II ("Nacionalismo"), del libro Politica y estrategia de desarrollo $(1977)^{24}$, en el que, según Capdevila, "resumió su concepción de la bistoria". ${ }^{25}$

20 Benítez, 1963.

21 Pérez \& Meo, 1980 (volumen apologético que reúne tres tomos publicados en 1972, 1975 y 1979).

22 Bourdieu define al habitus como un "sistema de las disposiciones socialmente constituidas que [...] son el principio generador y unificador del conjunto de las prácticas y de las ideologías características de un grupo de agentes" (Bourdieu, 2001: 239-240).

23 Palacios \& Payne, 2008: 54.

24 Stroessner, 1977.

25 Capdevila, 2010: 230. 


\section{La "misión providencial" de Francisco Franco}

Los textos de Franco reflejan las categorías, tópicos, filias y fobias características del consenso ideológico del "Movimiento Nacional". Su pensamiento y mentalidad histórica fueron influidos particularmente por "las ideas del tradicionalismo que integraba al legitimismo, el carlismo y a los posteriores movimientos del catolicismo político y los prefascismos". ${ }^{26}$

La incidencia del providencialismo histórico fue fundamental. Constituye la clave de bóveda del relato que articuló sobre el devenir de España y sobre su destino personal: un elegido por Dios para restituir las glorias nacionales, un hombre inspirado para "salvar" a la nación y acaudillar una "cruzada" contra los impíos republicanos. Sobre este background se fue moldeando la personalidad y la ideología antiliberal y antidemocrática - del "Caudillo".

Su mentalidad histórica se formó, durante la adolescencia, en la lectura de Benito Pérez Galdós y sus Episodios Nacionales. En esos textos novelados "se alimentó la incipiente afición por la historia de Franco" que derivó, con el tiempo, en el interés por las biografías de "los grandes personajes de la historia, empezando por los Reyes Católicos, de quienes llegó a ser, y lo fue siempre, un admirador apasionado". ${ }^{27}$ Posteriormente concentró su atención en el estudio de temas militares, políticos e ideológicos. Entre los pensadores que contribuyeron a definir su ideología política y su pensamiento histórico se destacan Marcelino Menéndez y Pelayo - fundamento intelectual de su "bipernacionalismo volcado a la retrospección nostálgica y a la identificación entre patria y ortodoxia católica $^{, 28}$-, Antonio Cánovas del Castillo ${ }^{29}$ y Salvador de Madariaga. ${ }^{30}$ En la década de 1920 consumía "literatura anticomunista y autoritaria enviada por la Entente Internationale contre la Troisiéme Internationale". ${ }^{31}$

En la producción del ferrolano no existe un texto doctrinal con la síntesis de su pensamiento histórico. Éste se expone en una gran cantidad de discursos, mensajes, entrevistas y libros en los que se perfila una concepción integral del devenir de

26 Eiroa, 2012: 78.

27 Merino, 2020.

28 Moradielos, 2018: 41.

29 Cf.: Orella, 1997: 145-167.

30 Cf.: González Cuevas, 1989: 145-181.

31 Moradielos, 2018: 29. 
España (de carácter providencialista) y un relato explicativo del mismo en base a una serie de categorías y entidades isotópicas que reflejan sus filias y sus fobias.

\section{Concepción integral de la Historia de España}

Franco tenía una concepción integral de la historia de España que expuso de manera coherente en un conjunto muy variopinto de textos. Integral porque estaba sostenida en una filosofía de la historia de cuño providencialista (que informaba el sentido de la misma en el contexto de la civilización occidental) y ofrecía claves explicativas claras (de carácter trascendente y por tanto indiscutibles) para las coyunturas críticas. Además, brindaba certezas para superar la crisis presente a través de la conducción de un "Caudillo" victorioso en una "Cruzada nacional", que actuaba por "la gracia de Dios" y estaba destinado a convertirse en "centinela de Occidente". ${ }^{32}$

La clave del providencialismo histórico de Franco se encuentra en la acción confluyente de varios factores entre los que se destacan su profunda fe, la convicción de que la "salvación" de España requería una acción decidida - que se materializaría en el "alzamiento nacional" - y el respaldo ideológico-funcional de la Iglesia católica.

Franco evidenció, en su vida pública, una adhesión muy fuerte a la institución eclesial que parecía corresponderse, en lo privado, con una fe sincera. Esto lo llevó a interpretar los acontecimientos - y el propio devenir - en clave trascendente. Es ilustrativa, en este sentido, una anécdota contada por su hija sobre una carta que le envió a Juan Perón - cuando el estadista argentino comenzó a tener conflictos con la Iglesia - en la que le advertía: "Juan Domingo, no olvides que nuestros regímenes son transitorios, mientras que la Iglesia es eterna",33

El anticlericalismo virulento del gobierno republicano favoreció la rápida adhesión de la jerarquía católica al Movimiento Nacional y a su líder. En las manifestaciones iniciales de apoyo al Caudillo por parte del episcopado, figuran algunas de las ideas que orientarían su pluma para explicar la historia de España. Resultó muy

32 Se trata de una denominación que se generalizó a partir de la publicación del libro Centinela de Occidente. Semblanza y biografía de Francisco Franco, de Luis de Galinsoga (1956).

33 Palacios \& Payne, 2008: 46. 
significativo el rol desempeñado por el cardenal Isidro Gomá y Tomás, Arzobispo de Toledo y Primado de España, quien bregó para el reconocimiento internacional de la legitimidad del alzamiento militar y lo definió como una "cruzada" de la civilización cristiana contra el ateísmo marxista.

Pero fue Enrique Plá y Deniel, obispo de Salamanca, quien contribuyó de manera decisiva para legitimar teológicamente el alzamiento militar y brindar insumos teóricos para la articulación de la explicación providencialista del mismo. Lo hizo en una carta pastoral titulada Las Dos Ciudades, difundida el 30 de septiembre de 1936, en la que justificaba - en clave agustiniana - la lucha apocalíptica que se desarrollaba en España entre la ciudad terrestre y la ciudad celestial, representadas por los "rojos" y los "nacionales". Explicaba la rebelión militar como una "cruzada" contra los comunistas y anarquistas por la "salvación" de España.

Ese documento constituye, en mi opinión, la hoja de ruta de Franco para revestir al "Movimiento" de una misión redentora. En declaraciones realizadas durante la guerra a un diario argentino, expresa con claridad la convicción de protagonizar una lucha de dos principios antagónicos - propia de las "dos ciudades" de San Agustín -: "de la Patria contra la antipatria, de la unidad contra la secesión, de la moral contra el crimen, del espiritu contra el materialismo". Este combate tenía por objetivo defender "la existencia e independencia de España frente al Comunismo tiránico que intentó rusificar nuestra alma". ${ }^{34}$

La psicología y el itinerario biográfico de Franco permiten especular en torno a que estaba convencido de que era efectivamente, como proclamaba el episcopado, un "homo missus a Deo" ${ }^{\circledR 5}$ que debía salvar a España, reactualizar su misión religiosa como custodia de la fe en Occidente y restituir la unidad indisoluble entre nacionalismo tradicional y fe católica. Luego de la guerra consideró que su "buena estrella" - o "baraka" ${ }^{36}$ de las campañas marroquíes - era, en realidad, un designio divino. Lo refleja en innúmeras oportunidades a través de la apelación al plural mayestático que no refiere, en esta ocasión, al movimiento nacional sino a un modismo casi pontifical, acorde a su carácter de Caudillo bendecido por Dios:

34 Franco, 1938.

35 Moradielos, 2018: 70

36 Palacios \& Payne, 2008: 347. 
Queremos salvar la continuidad sagrada de nuestra Historia frente a los que quieren hacer tabla rasa de los eternos principios que informan la vida española. Queremos asegurar a España por medio de su Revolución Nacional un porvenir lleno de justicia y prosperidad. Queremos, en definitiva, asumiendo una vez. más nuestro papel de Adelantados de la civilización, salvar al mundo entero de la ruina fatal y segura a que conduciría el triunfo del Comunismo. ${ }^{37}$

La evocación a la historia sagrada y la expresión de certeza en cuanto a una misión trascendente, revelan una auto-conciencia mesiánica. Lo dejó claro, por ejemplo, cuando con motivo de la celebración en Burgos de los veinticinco años de su "Exaltación a la Jefatura del Estado", expresó sus sentimientos al recibir en sus "manos el cuerpo exangüe de la Patria para salvarla y crear un Estado". 38

Negar la acción de Dios en el devenir es irracional, contradice la evidencia empírica. $\mathrm{Al}$ analizar el descubrimiento, conquista y colonización de América, advierte sobre la actitud de vanagloria de los protagonistas de "grandes sucesos", pues pierden la perspectiva al "ignorar aquella decisión providencial que suele convertirlos en actores de las grandes epopeyas históricas". Plantea con rotundidad que Dios tenía "reservado a España ese maravilloso alumbramiento a la fe católica de los pueblos de América". ${ }^{39}$ Las hazañas de Colón, Cortés y Pizarro, entre otros, no se concretaron por sus propios méritos, sino por designio divino, porque obedecieron al "destino histórico" de España, que había sido elegida por una "voluntad superior" para "ser cabeza de la gran epopeya". 40

La historia reciente, la de la Guerra Civil, también está revestida de dimensiones sobrenaturales. En ocasiones la causalidad racional es ignorada en aras de justificar la intervención divina en beneficio de los nacionales. Este hecho constituye una prueba contundente de la justicia - en términos teológicos - del alzamiento. Es así, por ejemplo, en un hecho aparentemente "milagroso" como la captura - literalmente "Ilovida del cielo" destinado a los "rojos", o en ocasiones puntuales en que el desenlace favorable de ciertas batallas se producía en días de solemnidades religiosas.

37 Franco, 1938 b.

38 Franco, 1961

39 Franco, 1953.

40 Franco, 1954 a.

41 Franco, 1954 a.. 
En 1960, con motivo del mensaje de fin de año, Franco se congratulaba por "los largos años de pary de actividad que la Providencia viene concediéndonos". ${ }^{42}$ Instaba a los españoles a seguir alertas en la lucha contra los agentes de la "ciudad del mal" que, desde el exilio, conspiraban para alterar la marcha feliz de la nación por los carriles de su destino eterno.

\section{La historia en acción: filias y fobias de un Caudillo "por la gracias de Dios"}

¿Cuáles son, efectivamente, los hitos fundamentales, los procesos más importantes y la trama general de esa historia, "libretada" por Dios, que tiene como actor y autor al Caudillo?

El ferrolano articuló el relato de la historia de España de forma dialéctica y simplista. Consideraba que la Edad Media fue una etapa fermental, "caracterizada por la lucha contra el Islam - la Cruzada, la Reconquista - y la consecución de la unidad política”. Con el gobierno de los Reyes Católicos, "artifices de la unidad nacional", comenzó el "apogeo de la nación" que prosiguió "esplendorosamente durante el Siglo de Oro con la conquista de América y el Imperio de los Austrias en Europa”. La decadencia comenzó en el siglo XVII y prosiguió hasta el siglo XX, "la II República constituyó su punto más bajo: como nefasto ejemplo de la degradación nacional y de la perniciosa influencia extranjera" ${ }^{43}$ Consideraba que la monarquía, durante el período de decadencia, pierde prestigio y eficacia, ya

no proyecta hacia el exterior el genio de España, sino que recibe, acoge y ensalza lo que la anti-España concibe allende las fronteras, y que culmina con la invasión enciclopédica y masónica que patrocinan Floridablanca y el conde de Aranda, que fatalmente tenía que terminar ennobleciendo banqueros $y$ especuladores: los mismos que en los últimos años suscribieron el socorro [rojo] internacional y ayudaban a los periódicos marxistas. ${ }^{44}$

Presenta al devenir como una lucha de patriotas y traidores, de españoles contra antiespañoles. Se trata de una explicación simplista que ocultaba contradicciones

42 Franco, 1960.

43 Alares, 2020: 55-56.

44 Franco, 1942 (carta de Franco al Conde de Barcelona, mayo de 1942, en Fontana, 1999: XIII-XIV). 
socio-económicas, culturales, políticas y de mentalidades muy profundas. Plantea la existencia de una identidad nacional, un "carácter español” propio y único, que constituiría un continum, fácilmente identificable desde la Edad Media y cuyas raíces estaban en la antigüedad. Uno de sus mejores modelos es el Cid Campeador "símbolo de la reciedumbre y del Señorío de una raza. [...], es el espiritu de España"*5 - que debía inspirar al Movimiento Nacional para cumplir la misión de reconstruir la nación.

Transmitía un discurso sencillo, entendible y simplificador. Ofrecía certezas para el ciudadano que lo escuchaba o lo leía y que estaba sufriendo los temores e inseguridades de las décadas de 1930 y 1940. Brindaba esperanzas de superación de los problemas apremiantes del presente; lo hacía apelando a las fortalezas del carácter español, ese que en el pasado había sido capaz de mil hazañas. Se trata de una construcción discursiva global de carácter performativo y de alta eficacia de embelesamiento de las masas. Constituía un mantra repetido por el dictador en encuentros multitudinarios - realizados con motivo de acontecimientos o celebraciones puntuales como el milenario de Castilla (1943) o el quinto centenario de la muerte de Carlos V (1958), entre otros -, y en las alocuciones cotidianas del “calendario litúrgico" del régimen (discursos pronunciados ante las Cortes, mensajes de Navidad, evocación de la victoria en la Guerra Civil).

La apropiación del pasado con fines legitimadores era absoluta. Algunos de los ejemplos más claros fueron la utilización de conceptos como "Cruzada" y de procesos como la Contrarreforma, que se actualizan en la lucha contra el comunismo y la masonería. Las categorías y argumentaciones usadas adquieren carácter isotópico y reflejan, en última instancia, las filias y las fobias del autor. Lo hacía mediante un relato maniqueo que explicaba el devenir de forma dicotómica: España, el Imperio y la fe católica, por un lado; la anti-España, el comunismo y la masonería, por otro. Ese planteo tenía dimensiones diacrónicas (oposiciones, fundamentalmente de carácter fáctico, en el devenir) y sincrónicas (dicotomías políticas e ideológicas en la contemporaneidad de los hechos narrados o en el propio presente del autor).

45 Franco, 1955 a. 
Este modelo argumental se aprecia con claridad en la articulación del relato sobre del "Alzamiento Nacional" y la "Cruzada" (Guerra Civil). Repitió hasta el cansancio que el ejército español no se sublevó, porque no le era lícito hacerlo, pero sí debía "levantarse en armas para defender a la Patria" cuando esta se encontraba en "peligro de muerte". ${ }^{46}$ Invierte la carga de la prueba y sostiene que los sublevados eran los "rojos" pues violaron su propia Constitución y leyes electorales, infringieron derechos fundamentales (vida y propiedad), aplicaron medidas que favorecieron el caos social y no respetaron la soberanía nacional (al someterse a las orientaciones de Moscú). El Alzamiento fue un hecho ineludible para la "verdadera España" en un momento en que, desde su perspectiva, las opciones eran la vida o la muerte de la Patria.

El levantamiento de 1936 constituye un antes y un después en la historia. Lo describe mediante un contraste de luces y sombras. La guerra fue la "la coronación de un proceso histórico", supuso la lucha "de la Patria con la antipatria, de la unidad con la secesión, de la moral con el crimen, del espiritu contra el materialismo y no tiene otra solución que el triunfo de los principios puros y eternos sobre los bastardos y antiespañoles". ${ }^{47}$ Una lucha de contrarios, una guerra de liberación, que se dirimía en una escala nacional pero que, en el discurso de Franco, adquiría - especialmente en el período más álgido de la Guerra Fría proyecciones universales: suponía una suerte de nueva batalla de Lepanto, de protección de la civilización cristiana y occidental (su esencia y tradiciones) frente al avance del comunismo internacional (materialista y ateo).

La defensa de la civilización cristiana adquiere, en la conceptualización del ferrolano, dimensiones supratemporales. En el discurso pronunciado el 2 de abril de 1959, con motivo de la inauguración del Valle de los Caídos, afirmó que

la lucha del bien con el mal no termina por grande que sea su victoria. Sería pueril creer que el diablo se someta; inventará nuevas tretas y disfraces, ya que su espíritu seguirá maquinando y tomará formas nuevas, de acuerdo con los tiempos. La anti-España fué vencida y derrotada, pero no está muerta. ${ }^{48}$

46 Franco, 1937.

47 Franco, 1938 a.

48 Franco, 1959. 
No se podían bajar los brazos ante el peligro comunista. Era necesario, en ese sentido, mantener "vivas de generación en generación las lecciones de la Historia para hacer fecunda la sangre ${ }^{\text {^9 }}$ de los mártires de la Patria. La admonición ciceroniana informó toda la producción del Caudillo y la práctica de la Historia durante su mandato.

La Cruzada representó uno de los acontecimientos más significativos de la historia de España. Lo asemeja "al que los Reyes Católicos realizaron al cambiar el signo de la nación en otra época de revueltas y de turbulencias, rebasando los limites nacionales para tomar naturaleza en el acaecer de lo internacional". ${ }^{50}$ Plantea un parangón de su accionar con el de Fernando e Isabel en cuanto a la culminación de un proceso de liberación nacional de la presencia de elementos extranjeros, una lucha para instaurar la verdadera fe y la unidad política.

La masonería constituyó una obsesión para Franco. Fue un tema presente en muchos de los artículos que publicó en el diario falangista Arriba. Esos artículos tienen un fuerte anclaje histórico en el que procura demostrar la existencia de una conspiración internacional contra España. Se publicaron posteriormente en formato libro con el sencillo título de Masonería ${ }^{51}$, en el que pretende desmentir las falacias esbozadas por "la mayoría de los historiadores liberales" s2 sobre el origen, evolución y significado verdadero de la masonería.

Considera una necesidad urgente compendiar en un volumen los textos en que revelaba el peligro de la conspiración masónica, un "cáncer que corroe a nuestra sociedad" escudándose en el secreto. Afirma de modo contundente que las logias socavaron el imperio español, maquinaron todo el proceso que culminó con la expulsión de los jesuitas y convirtieron el "siglo XIX en un rosario sin fin de revoluciones y de contiendas civiles" ${ }^{53}$ Felipe Wharton introdujo la masonería en España en 1728 y desde entonces conspiró, animado por las logias de Francia e Inglaterra, contra la fe, unidad y grandeza de la nación. El Movimiento Nacional tuvo por objetivo eliminar ese mal que, junto con el comunismo, estaban minando el desarrollo de la patria.

49 Franco, 1959.

50 Franco, 1952.

51 Boor, 1952.

52 Boor, 1952: 4.

53 Boor, 1952: 5. 
El ferrolano, fungiendo casi como un historiador, repasa las conspiraciones masónicas desde el reinado de Carlos III. Enumera el daño que causaron en virtud de su ideología atea y antinacional. Afirma que fueron masónicos "todos los movimientos revolucionarios que en siglo y medio se suceden en nuestro territorio, y los de secesión de nuestros territorios de América" y los que "entregaron España a las Brigadas Internacionales y a las checas y comisarios de Moscú". ${ }^{4}$ Advierte que el rechazo de la ONU hacia España se debía a la acción de los masones que ocupaban cargos importantes en la organización.

Otra idea recurrente fue la del Imperio. El concepto sufrió una metamorfosis importante en función de los avatares históricos. Inicialmente, en la etapa final de la Guerra Civil y en los años de coqueteo con la Alemania de Hitler, el Caudillo "creyó firmemente que estaba destinado a formar un nuevo gran imperio español, principalmente en el Magreb" ${ }^{55}$ Posteriormente, cuando los acontecimientos europeos y el período de aislamiento demostraron la fatuidad de tal proyecto, la noción adquirió ribetes más espirituales: viró del norte de África hacia América y se conoció como idea de Hispanidad, una reconversión pacifista y cultural de la vieja "vocación imperial de España, depositaria de una misión histórica desde tiempos inmemoriales" ${ }^{56}$

El fortalecimiento de las relaciones fraternas entre la "Madre Patria" y sus excolonias americanas se procesó como una suerte de estrategia para recuperar la "grandeza de España" en base a la exaltación de su obra civilizadora en el Nuevo Mundo. Se potenciaron los nexos culturales, religiosos, lingüísticos y de "raza" que daban forma al concepto y resultaron de utilidad, según Beatriz Figallo, para "adheriry alegar en favor del modelo español - diferenciado de los nazi-fascismos derrotados en 1945 -, reivindicar la idea de neutralidad y figurar al franquismo" como movimiento superador del "liberalismo y el marxismo" que exaltaba las tradiciones comunes hispánicas para configurar una "identidad de destino". ${ }^{57}$

La "hispanidad" fue un concepto recurrente en las alocuciones y textos históricos del Caudillo. Lo definía, sencillamente, como la "gran comunidad de los pueblos hispánicos"58,

54 Boor, 1952: 20.

55 Palacios, Payne, 2008: 237.

56 Duplá, 2002: 175.

57 Figallo, 2018: 94.

58 Franco, 1955 b. 
originada sobre vínculos creados en base a una relación de igualdad, no de sojuzgamiento, entre la metrópoli y sus colonias (que eran "partes de una misma nación, con los mismos derechos, como otras Españas, que asi se llamaban $\left.{ }^{, 59}\right)$. Se trataba de vínculos que habían trascendido el período colonial y adquirido carácter supratemporal. Consideraba, en base a esta interpretación tan particular, que la hispanidad tenía una dimensión inmensa y polisémica. Refería a los valores comunes de la civilización cristiana. Creía que la unificación de esas naciones era esencial para la defensa de Occidente frente a la amenaza disolvente del marxismo soviético. ${ }^{60}$ España y sus antiguas colonias tenían, en ese sentido, el gran desafío de ser ejemplo para el mundo en la empresa de contribuir a la instauración de la paz y el progreso a nivel internacional.

El triunfo del Movimiento Nacional y la construcción de la nueva España requirieron de una épica legitimadora, engarzada con el pasado glorioso de la nación. Hechos como la defensa del Alcázar de Toledo, "Belchite, Alcubierre, el crucero Baleares', Brunete, Teruel y el Ebro, han quedado para siempre, con otros numerosos nombres gloriosos, grabados en el libro de la Historia". ${ }^{1}$ Para evocar esas glorias y homenajear a sus mártires se construyó una obra faraónica, emulación en cierto sentido de El Escorial de Felipe II, el Valle de los Caídos. Con esa iniciativa, Franco pretendió escribir en piedra una página que consideraba épica: la del martirio, por la grandeza de España, de aquellos que combatieron contra los ateos comunistas y anarquistas. Se trata de un complejo monumental destinado a subyugar a las masas a través de un sentimiento de trascendencia y a expresar el espíritu de unidad de la Nueva España.

\section{Alfredo Stroessner y la "segunda reconstrucción" de Paraguay}

59 Franco, 1954 b.

60 Esta idea fue una obsesión de Franco. En 1938 afirmaba de modo categórico, en declaraciones a La Nación de Buenos Aires, que se sentía asistido "por el recio espíritu de los países americanos que, como nosotros, comprenden la magnitud de la contienda. Este honor nuestro es honor de la raza y su prestigio abarca por igual a todos los pueblos de origen hispánico. [...] Preciso es que conozcan en América el hondo sentido humano y justo de nuestra guerra. Nuestro heroico Ejército [...] está realizando un magno servicio en defensa de la civilización universal“ (Franco, 1938 b).

61 Franco, 1956. 
En los escritos de Alfredo Stroessner desemboca y se canaliza el torrente nacionalista nacido en el pensamiento de Juan O’Leray y Juan Natalicio González. Abrevando de esas fuentes, el autócrata organizó un relato aislacionista, heroico y autosustentable que resultaba funcional a sus intereses. Suponía que los problemas del presente y la prosperidad del futuro dependían del advenimiento de dirigentes esclarecidos y del apoyo del ejército. El autoritarismo del presente era convalidado por una pedagogía de la historia que exaltaba la acción de los "hombres fuertes" que fundaron la nacionalidad y sostuvieron su independencia. El encarnaceno apela a la "verdad histórica" expuesta y "demostrada" por los autores del "revisionismo histórico" para articular un relato que pretendía llenar de sentido el devenir de la nación.

Las virtudes de los héroes de la "edad de oro" de Paraguay se reflejaban en la persona del prohombre del presente. Sus textos - además de su práctica de gobierno - estaban saturados de pretérito y materializan lo que Adriano Irala Burgos denominó "ideología de la Segunda Reconstrucción”. Id Ideología de sustentación del régimen, inspirada en la tradición autoritaria paraguaya. Supone la caracterización de Stroessner como "salvador" del país luego de un período anárquico (el de hegemonía del Partido Liberal) y su identificación con el general Bernardino Caballero (presidente entre 1880-1886), el "primer reconstructor" de la nación luego de la tragedia de la Guerra de la Triple Alianza. Se ubica, de esta forma, en una línea de continuidad con los gobernantes de la "edad dorada" de Paraguay: José Gaspar Rodríguez de Francia, Carlos Antonio López y Francisco Solano López.

El "Segundo Reconstructor", por tanto, refleja en el presente la inteligencia, abnegación, heroísmo y probidad del general Caballero, quien había recibido la posta de mando directamente del mariscal López y fue fundador de la Asociación Nacional Republicana (Partido Colorado). En sus textos, Stroessner acostumbraba a enumerar los logros materiales de su gobierno (materializados gracias al programa de "Paz y Progreso" que había inaugurado en 1954). Las tramas argumentales tienden a "demostrar" que su administración reactualiza la "edad dorada" del Paraguay.

La producción del encarnaceno puede clasificarse, a los efectos analíticos, en dos categorías: documentos doctrinales y textos instrumentales. Entre los primeros

62 Irala Burgos, 2003: 214. 
ocupa un lugar preponderante el capítulo II del libro Política y estrategia de desarrollo (1977), en el que sintetiza de manera clara y contundente su interpretación general de la historia y sienta cátedra sobre la funcionalidad de la misma en el presente. Entre los segundos se ubican un conjunto de discursos y proclamas en los que, por decirlo de alguna manera, la historia se pone en "acción”, las definiciones teóricas adquieren aplicabilidad militante (a través de la censura de partidos, la condena personas y el elogio de ciertas prácticas y actitudes).

\section{Documento doctrinal}

El capítulo II de Política y estrategia de desarrollo es la summa doctrinaria del pensamiento stronista sobre la historia paraguaya. Sintetiza de manera cabal la utilización del pasado para legitimar el gobierno de la "segunda reconstrucción" y a su conductor, una suerte de general Caballero redivivo. Debe considerarse como un ensayo político informado por la impronta de O'Leary en los aspectos fáctico-interpretativos y por las concepciones de Natalicio González en lo que refiere a la filosofía de la historia. La interpretación general del devenir corresponde in totum a los aportes realizados por el "reivindicador de las glorias nacionales". Esto se aprecia en la presentación de la historia paraguaya como la epopeya de un pueblo extraordinario, amojonada por una guirnalda de biografías heroicas y que supo demostrar su valía en dos coyunturas bélicas sin parangón en los anales americanos (la Guerra de la Triple Alianza y la del Chaco). Las estrellas mayores de ese firmamento de "grandes personajes" lo encabezan cuatro "hombres fuertes" del siglo XIX: José Gaspar Rodríguez de Francia, "el dictador irreductible, que cerró sus oídos al mundo exterior, pensando asi que preservaba la Independencia de su Patria"; Carlos Antonio López, el "estadista prócer, que dio jerarquía internacional y poderío moral y material a la República”; Francisco Solano López, "simbolo del heroismo en la más alta elevación del hombre" ${ }^{33}$; y Bernardino Caballero, héroe de la Guerra de la Triple Alianza y fundador del Partido Colorado, asociación política "que debia cargar sobre sus hombros la restauración y el surgimiento de la Patria". ${ }^{64}$

63 Stroessner, 1977: 74.

64 Stroessner, 1977: 84. 
Los protagonistas de la epopeya son militares heroicos (que ofrendaron la vida en cruentas batallas por la dignidad y la soberanía nacional) o civiles preclaros (verdaderos estadistas) que aprovecharon los tiempos de paz para laborar en pro de la grandeza de la patria.

El relato histórico está mixturado por el discurso del autor que tiende a "demostrar" la veracidad de un conjunto de asertos indiscutibles y de carácter performativo: la afirmación del lopizmo como ideología oficial y dogma indiscutible de la nacionalidad paraguaya; una interpretación maniquea del devenir nacional, articulado en clave dialéctica de lucha entre paraguayos y anti-paraguayos; la mimetización de Stroessner con el general Caballero. En la construcción discursiva López es presentado como referente de heroicidad y Caballero como modelo de acción política y gestión gubernamental.

El mariscal López es el pantocrátor del panteón nacional. Tanto la administración como los escritos de Stroessner culminan el proceso de entronización del personaje, que había comenzado en 1900 con la prédica de O’Leary y se había acelerado a partir de 1936 con el advenimiento del febrerismo. El autócrata subraya que López "no fue el tirano que sometía a sus seguidores por obra del miedo", sino "la encarnación de un sentimiento colectivo inspirado en la justicia”. ${ }^{5}$ Eleva el culto a López a niveles sorprendentes. Su imagen y su nombre se imponen en el nomenclator, las efemérides, los libros de texto, el papel moneda y en las instituciones (culturales, militares).

La figura del mártir de Cerro Corá se vuelve omnipresente y su culto veneración. Ser anti-lopizta es sinónimo de anti-paraguayidad. En un comentario breve, de carácter sentencioso, se advertía que "el pueblo sabia que ser desertor del ejército de López era ser desertor de la Causa Nacional". ${ }^{66}$ La mínima crítica al mariscal deviene, en este sentido, delito de lesa nación:

El Paraguay de hoy admira y hace un culto de la memoria del Mariscal Francisco Solano Lóper, ante cuya figura, simbolo de la personalidad heroica y gloriosa de la nación, no permitiremos que existan mentes que ni siquiera nos discutan nuestra decisión de aplastar los resabios que intenten supervivir con los auspicios de los legionarios resucitados para destruir la paz fecunda y orgánica de

65 Stroessner, 1977: 84.

66 Stroessner, 1977: 83. 
que gozamos, y la marcha victoriosa de nuestro país hacia la cumbre de su destino luminoso. ${ }^{67}$

Cuestionar al mariscal y a las demás figuras equivale, por transitiva, a cuestionar la nación y a los representantes de la misma, el Partido Colorado y su líder:

Jamás permitiremos que se anule en nuestras manos un legado con sangre de mártires de la nacionalidad. No perdonaremos ningún renunciamiento sospechoso, ninguna duplicidad condescendiente, ninguna actitud vacilante, cuando están en juego los supremos intereses de la Patria. Emplearemos sin titubear todas las facultades que el pueblo puso en nuestras manos para llevar adelante nuestros planes constructivos y salvar del retroceso, del escarnio y de la vergüenza a la Nación. ${ }^{68}$

El autócrata divide a la sociedad paraguaya entre "buenos" y "malos", patriotas y legionarios. ${ }^{69} \mathrm{El}$ maniqueísmo se convierte en instrumento para analizar la realidad contemporánea y definir a los potenciales enemigos internos y externos (en particular el marxismo). El gran enemigo de Paraguay y de América es el "comunismo internacional" que desde su base cubana pretendía subvertir el orden tradicional y democrático de los países americanos. Hay un rechazo total al "procedimiento foráneo que propugna unificar los sentimientos de los pueblos bajo la férula de ideologías importadas, que por el solo becho de ser importadas, atentan contra nuestras seculares convicciones". ${ }^{70}$ La historia paraguaya es presentada, en este sentido, como una lucha entre dos principios enfrentados, el nacionalista y el legionario (liberales, marxistas). Quienes renegaban del primero "no podrán nunca ser forjadores del porvenir y los creadores de la grandeza de la República". ${ }^{71}$ Los marxistas son los nuevos legionarios que merecen desprecio y condena.

Caballero es el espejo en el que se mira Stroessner, la imagen que quiere reflejar sobre el pueblo que conduce. Caballero es el fundador del Partido Colorado, colectividad a la que pertenece el autor y que reivindica como herramienta privilegiada - y

67 Stroessner, 1977: 87-88.

68 Stroessner, 1977: 82.

69 Término despectivo utilizado como sinónimo de traidor. Originalmente se refería a los paraguayos exiliados en Argentina que, en la coyuntura de la Guerra de la Triple Alianza, combatieron a favor de las fuerzas aliadas. Para mayor información ver el completo estudio de Claudio Fuentes Armadans sobre el tema (Fuentes Armadans, 2016).

70 Stroessner, 1977: 87.

71 Stroessner, 1977: 79 
excluyente - de la seguridad y el desarrollo nacional. El "Centauro de Ibicuy", por otra parte, supo ser "béroe en la Guerra" y "bacerse héroe en la Paq", es decir, luchar junto al mariscal en el terrible conflicto del ' 70 y reconstruir posteriormente al país. Stroessner también combatió por la patria en defensa de los territorios chaqueños y lucha desde la presidencia de la República por el progreso nacional luego de la "larga noche" de hegemonía del Partido Liberal.

La ideología de la segunda reconstrucción plantea, como una idea fuerza, que el "cauce del progreso" se detuvo en Cerro Corá. Se trata de un hiato cronológico de un siglo, una verdadera fractura temporal, que exigía a Stroessner y a sus contemporáneos reatar "el bilo de la historia",3 hilvanar una trama coherente entre aquella "edad dorada" y ese presente venturoso. Pocas luces se rescatan de esa fase de oscuridad (la gestión de Caballero, la lucha de O’Leary por reivindicar a López, la Guerra del Chaco). Son hitos que demuestran la supervivencia del patriotismo y la gestación de las condiciones para la emergencia de un líder que restauraría la dignidad nacional.

Los logros materiales del presente stronista (construcción de rutas, represas, inauguración de centro de enseñanza) se ubican en un continuum con los concretados, por ejemplo, por Carlos Antonio López.

La emergencia frecuente del yo narrador para referirse a su gobierno - "Mi corazón de paraguayo..."; "Mi gobierno...."; "Mi interés fundamental..." - y la utilización del plural mayestático para mentar la labor del Partido Colorado, son las estrategias discursivas utilizadas por el autor para subrayar la identidad entre ambos "reconstructores", la legitimidad de su autoridad y la vigencia de la colectividad política para gestionar los cambios que consolidarían la marcha del Paraguay hacia su destino de grandeza. El líder y su partido eran herederos de las glorias militares de López y Caballero, glorias reeditadas por "quienes twimos el honor de defender en los cañadones chaqueños" la "integridad moral y territorial" " de la Patria.

El texto está sustentado en una filosofía de la historia que abreva directamente de las concepciones de Juan Natalicio González. Este pensamiento se expresa a través de 
la, ya referida, concepción dicotómica de la historia - entre los defensores del "Ser Nacional" y sus enemigos "los internacionalismos" (liberalismo, marxismo) ${ }^{75}-$ y la apelación sutil - pero directa - de categorías formuladas por González en el ensayo El Paraguay Eterno (1935).

Para González, la identidad nacional se habría definido desde "los inicios de la conquista" y se desenvolvió conforme a una "ley natural" predeterminada por el "triple influjo de la tierra, de la raza y de la historia". ${ }^{77}$ Stroessner asume esa concepción esencialista de la nación:

Cuando la estrella de la libertad brilló de pronto en el cielo de las banderas de América, ya habia en nuestra tierra con anterioridad un pueblo enamorado de su propio destino. [...] Asunción, genitora de ciudades [...]; Asunción, la ciudad de Mompóx y de Antequera, debia ser 'la cuna de la libertad de América' [...]. Con los Comuneros ya nacía en el alma de los paraguayos de entonces la estrella solitaria de nuestro escudo. [...] Y fue una estrella la que se encendió en el corazón del Mariscal Francisco Solano López para alumbrar desde entonces los confines de la Historia. Es de ese pueblo que los paraguayos somos herederos de sangre y espiritu". ${ }^{78}$

En última instancia, La Política y estrategia del desarrollo propuestas por el autor, se fundamentan en la fortaleza del nacionalismo. Esta "radica esencialmente en un sincero amor a la tierra en que nacimos" ${ }^{\$ 9}$ y en la emulación del heroísmo del mariscal López, "pensamiento y espada del Paraguay Eterno" de una raza de hacerse respetar en el escenario del mundo". ${ }^{1}$

La clave de bóveda para lograr la "Paz y el Progreso" propuestos por el stronismo radicaba en asumir los valores del Paraguay Eterno que emergen, como planteaba González, del "triple influjo de la tierra, de la raza y de la bistoria". Solo de esa forma sería posible reatar "el hilo de la historia" ${ }^{83}$ entre la "edad dorada" (el Paraguay de los López) y el presente de Stroessner para que la nacionalidad vuelva "a ser ella misma". 84

75 Velázquez, 2018: 7.

76 Velázquez, 2018: 7.

77 González, 1935: 60.

78 Stroessner, 1977: 73.

79 Stroessner, 1977: 79.

80 Stroessner, 1977: 74.

81 Stroessner, 1977: 83.

82 González, 1935: 60.

83 González, 1935: 76.

84 González, 1935: 60. 


\section{Textos instrumentales}

La manipulación y aplicación instrumental del conocimiento histórico realizadas por Stroessner se aprecia con total claridad en un conjunto de discursos y proclamas, dirigidos a públicos concretos y sectorizados.

La evocación de las enseñanzas de la historia para justificar el programa de "paz y progreso" imperantes en el presente "democrático" es constante en las intervenciones públicas del autócrata. "Paz" impuesta coercitivamente y sostenida por el estado de sitio. "Progreso" medido cuantitativamente en kilómetros de rutas, inauguración de represas, creación de escuelas, entre otro tipo de "obras" (pero con escasas iniciativas de transformación estructural del aparato productivo que asegurara una distribución equitativa de la riqueza). "Democracia" manejada por el Partido Colorado, con elecciones amañadas y pequeños grupos "opositores" que se prestaron, a cambio de prebendas, a participar de elecciones que terminaban avalando el triunfo la Asociación Nacional Republicana.

"Paz", "progreso" y "democracia" adaptadas a la realidad paraguaya, según la interpretación de Stroessner, y justificadas por una retórica patriótica asfixiante. Los discursos ante el Congreso o ante la convención del Partido Colorado, los mensajes a la ciudadanía con motivo, por ejemplo, de la Navidad y las notas a organismos internacionales presentan una fuerte isotopía discursiva que deja pocos intersticios para la crítica. Se trata de conceptos performativos, de "realidades" ya plasmadas o próximas a materializarse, enunciados por el líder que tiene los recursos y la legitimidad para concretarlas. Son textos instrumentales en los que la inercia del pasado adquiere dinámica y se concreta en la pretensión de reatar el hilo de la historia, de reactualizar los logros de la "edad de oro" de los López.

Hay coherencia entre los discursos de la primera hora y los de las postrimerías de su mandato. La isotopía discursiva permanece, por ejemplo, en la alocución de Stroessner ante la convención del Partido Colorado, los días 21 y 22 de febrero de 1987, aceptando su postulación presidencial para las próximas elecciones. En esa ocasión manifestó su felicidad por presentarse ante "los legítimos representantes del pueblo 
colorado" que deberían resolver cuestiones "de máxima importancia estrechamente vinculadas con la paz y el progreso de la República". Argumenta que desde su primera gestión gubernativa estuvo inspirado "en los postulados luminosos y broncineos del nacionalismo paraguayo". 85

Plantea que las grandes realizaciones materiales de sus gobiernos se concretaron gracias a que lo guiaba "la verdad" y la "brújula de la historia". Actuaba inspirado en "la lección de Patria" de sus "mayores". 86 Pontifica en base a argumentaciones indiscutibles, a dogmas de cuño pretérito que habían permeado los distintos estratos sociales. La historia le permite hacer, el pasado lo impulsa a crear, por ese motivo,

Donde nada se construye, donde nada se inaugura, donde nada se hace, no hace falta mi presencia. Asisto a los actos que patentizan el esfuerzo creador. Estoy en las ceremonias que habilitan obras que dan satisfacción a las necesidades sociales, en todos los sitios en los que el trabajo da sus frutos, con proyección social. Aquel que sólo busca su beneficio personal, no es patriota. Aquel que apenas se mueve en función de su egoismo estrecho, no es colorado. ${ }^{87}$

Efectivamente, procuraba estar en todas las inauguraciones. Se aseguraba de que, en el imaginario colectivo, se lo asociara con un hacedor, con el padre de la Patria dador de todos los bienes. Un hombre providencial con el cual era necesario renovar quinquenalmente el contrato político. Para la colectividad que se beneficiaba con su gestión, para el pueblo influido por la propaganda oficial y para los ciudadanos temerosos de la tan glosada "anarquía", era una responsabilidad patriótica votarlo (como lo hacían desde 1954).

La "paz" y el "progreso" eran posibles por la "democracia irrestricta" que, en su concepto, se gozaba desde 1954. Un concepto de democracia muy particular que se expresaba, por ejemplo, en la negación del abstencionismo, de la posibilidad del voto en blanco o de la participación de partidos de inspiración marxista. A los promotores de estas prácticas se les tildaba de "fracasados políticos", antidemocráticos porque "actúan como esbirros de la subversión internacional". La "democracia stronista" es una "democracia sin comunismo". Por mandato de la historia "nuestra raza no acepta amos ni 
tutores" y seguiría gozando de "pazy de felicidad [...] porque manda y seguirá mandando el gran Partido Colorado". 88

Las expresiones de 1987, consideradas de manera aislada, parecen contener un repertorio de profecías autocumplidas. En realidad, se trata de un recurso utilizado ya en los discursos de 1954 cuando afirmaba, en el marco de un acto ante "el pueblo colorado" (en el que aceptaba la invitación formulada por la Junta de Gobierno del Partido para ser candidato a la presidencia), que se proponía encarar una gestión de hechos y no de palabras. Ponía énfasis en la necesidad de explotar de forma intensiva el suelo, construir rutas nacionales e internacionales que unieran los distintos puntos del país (en especial el Chaco) y desarrollar las potencialidades de la red fluvial para el desarrollo del comercio. Lo hacía en virtud de cumplir un "mandato irrenunciable" proveniente del fondo de la historia, de la "visión grandiosa de Carlos Antonio López"."

Ese legado histórico era asumido por el Partido Colorado, "el gran obrero de la bistoria" 90 , una colectividad eterna, "como eterna es la Patria" y consubstanciada integralmente con la misma ("expresión genuina, social, política, económica, geográfica e histórica de la Patria Paraguaya"). Postula una historia en acción, un legado constructivo que se asumía plenamente y cuyos principales referentes era Caballero (fundador del Partido) y O’Leary (reivindicador de los héroes y también colorado). El "centauro de Ibycuy" y el "cantor de las glorias nacionales" dan forma a un legado heroico que integra "la espada y la pluma de la Patria"."1

La actualización de los logros de la "edad de oro" se canalizaría por la labor del líder, con el respaldo de la colectividad política y de las Fuerzas Armadas: la "unión granítica" que, en los hechos, garantizaría tres décadas y media de hegemonía política.

En el "Mensaje presidencial a la Honorable Cámara de Representantes" de 1961, el encarnaceno detalla las obras materiales concretadas por su gobierno y los esfuerzos realizados para contener la acción de los grupos insurgentes que, desde el exterior amenazaban, la soberanía nacional. Destaca la construcción de rutas, de centros de enseñanza, el incremento de naves de la marina mercante, el comienzo de "la marcha

88 Stroessner, 1987.

89 Stroessner, 1954 a.

90 Stroessner, 1954 a.

91 Stroessner, 1954 a. 
hacia el Este, a través de nuestras selvas hacia el Río Paraná", realizada con la colaboración de Brasil, hecho que "eterniza la unión y la cooperación de nuestros pueblos, para que nuestro país camine por tierra hacia el Atlántico". "Condena a los grupos subversivos de inspiración marxista ${ }^{93}$ que atentan desde el exterior y amenazan la "estabilidad democrática" y a la práctica abstencionista de los partidos opositores responsables de "deserción antipatriótica".

Protesta fidelidad a los principios de la "auténtica democracia" y se manifiesta como defensor de "los postulados que informan la civilización cristiana occidental". Explicita la solidaridad de su gobierno con los principios del Panamericanismo. Elogia la política del John F. Kennedy y censura la situación de Cuba ("país ocupado por los comunistas, que pretende penetrar en cada uno de nuestros países para convertirlos en juguetes o instrumentos [...] al servicio de oscuros designios imperialistas"). ${ }^{94}$

El repertorio de obras enunciadas, la defensa de la soberanía y la definición de una línea de acción clara en política internacional reflejan el espíritu del "Paraguay eterno". Logros posibles en virtud de que "reatamos el bilo de nuestra historia en hechos resultantes y a concretados y a concretar". ${ }^{95}$

Podríamos seguir analizando otros discursos y mensajes, pero sería abundar en exceso. Durante los treinta y cinco años de acción gubernativa, se aprecia una intensa isotopía discursiva que tuvo escasas excepciones (pautadas fundamentalmente por razones de política internacional con Argentina y Brasil en $1954^{96}$ y $1961^{97}$, que se manifestaron en notorias elusiones relacionadas con la responsabilidad atribuida por el revisionismo a Bartolomé Mitre y Pedro II en el desencadenamiento de la Guerra de la Triple Alianza). El autócrata aprovechó distintos contextos enunciativos para reforzar su proposición argumentativa de "reatar el bilo de la historia" y de legitimar su rol de "segundo reconstructor" del Paraguay.

92 Stroessner, 1961 a.

93 "El Estado de Sitio prorrogado en reciente fecha, es una medida de seguridad en salvaguardia [...] frente a la empecinada actitud de los maleantes internacionales que han contratado los servicios de algunos malos paraguayos afectos a la línea de la política de Moscú, hoy trazada sobre el Caribe, para lanzarlos en una inútil tentativa de sangre contra nuestras poblaciones fronterizas, con la pretensión de interferir nuestra obra de progreso y anular los beneficios de nuestra paz" (Stroessner, 1961 a).

94 Stroessner, 1961 a.

95 Stroessner, 1961 a.

96 Stroessner, $1954 \mathrm{~b}$.

97 Stroessner, $1961 \mathrm{~b}$. 


\section{Conclusión}

Francisco Franco y Alfredo Stroessner apelaron al pretérito para legitimar sus gobiernos. Lo hicieron como todos los autócratas, pero a ellos los distinguió el hecho de no dejar la tarea exclusivamente en manos de historiadores leales. Se preocuparon por elaborar y publicar textos en los que expusieron de manera clara sus ideas e interpretaciones sobre el pasado nacional. Este procedimiento los transformó en actores y autores de la $\mathrm{h}[\mathrm{H}]$ historia.

La nación española y la nación paraguaya se manifiestan en el devenir de los respectivos pueblos, expresadas en un relato escrito con carácter de epopeya. Es una epopeya que se manifiesta en dos dimensiones: la del pueblo militante y la del pueblo triunfante. El primero transita en una dimensión temporal y disfruta de las concreciones materiales del régimen, expresión de "progreso" que es posible gracias a la "paz" impuesta por el líder esclarecido; el segundo habita el territorio de la memoria, se manifiesta en ocasión de los fastos de la patria (patriotas heroicos, mártires) y constituye el numen inspirador del líder.

Los textos estudiados presentan algunas similitudes que podrían identificarse como regularidades pasibles de manifestarse en otros contextos: la historia nacional como principal fundamento del régimen autocrático; concepción esencialista de la nación; identificación de una edad dorada que se pretende rescatar y restituir (la España imperial, el período de los López); demonización de gobiernos y personas que regentearon anteriormente los destinos de la nación; interpretación maniquea del devenir, pautada por la definición de una alteridad - enemigo ideológico y supranacional - que funge como fundamento de la acción y lucha del régimen e implica un enfrentamiento entre patriotas y antipatriotas (el comunismo en ambos casos, la masonería en la interpretación de Franco); la definición de tópicos referenciales de carácter pretérito (personas y hechos).

Una de las grandes diferencias entre los autores es la función histórica atribuido la Iglesia y al cristianismo. En la interpretación de Franco es un rol indisoluble y consubstancial al ser español; su relato, por otra parte, tiene una impronta 
providencialista que informa la interpretación general del devenir. En los textos de Stroessner el cristianismo y sus valores informan la historia paraguaya en cuanto nación integrada a la "civilización occidental"; pero la institución, por el contrario, está relativamente soslayada debido a que las tensiones existentes entre el dictador y las autoridades eclesiásticas, la convirtieron en una entidad relativamente disfuncional al discurso legitimador.

La historia escrita por los autócratas supone una "apropiación indebida" y deformada del pasado. Implica la dignificación de ciertas edades doradas y la elisión de épocas malditas. La "paz y el progreso" no son construcciones colectivas, sino logros obtenidos por el gobierno y dádivas concedidas por éste. El autócrata presenta a su pueblo un relato que ofrece certezas ante las situaciones caóticas del presente y tiene carácter terapéutico en cuanto contribuye - en virtud de la función performativa de los discursos históricos - a la sublimación de los males del pasado reciente. Se erige como guía mesiánico, verdadero salvador de la patria que se materializa en la persona de Stroessner como "Segundo Reconstructor" y en la de Franco como "Caudillo de España por la Gracia de Dios". 


\section{FUENTES}

Boor, J. [seudónimo de Franco, F.] 1952, Masonería, Gráficas Valera, Madrid.

Franco, F. 18 de julio de 1937, "Declaraciones para el diario ABC de Sevilla". Disponible en https://fnff.es/ [Consulta: 3 de febrero de 2021].

Franco, F. 27 de agosto de 1938a, "Declaraciones a la Agencia Havas". Disponible en https://fnff.es/ [Consulta: 3 de febrero de 2021].

Franco, F. 2 de noviembre de 1938b, "Declaraciones al corresponsal de La Nación de Buenos Aires". Disponible en https://fnff.es/ [Consulta: 5 de febrero de 2021].

Franco, F. 19 de octubre de 1952, "Discurso pronunciado en Segovia ante un Congreso de ex combatientes". Disponible en https://fnff.es/ [Consulta: 3 de febrero de 2021].

Franco, F. 12 de octubre de 1953, "Discurso en el día de la Hispanidad". Disponible en https://fnff.es/ [Consulta: 3 de febrero de 2021].

Franco, F. 4 de junio de 1954a, "Discurso en la cena de gala ofrecida al Generalísimo Trujillo". Disponible en https://fnff.es/ [Consulta: 10 de febrero de 2021].

Franco, F. 5 de diciembre de 1954b, "Declaraciones al Director de Alerta de la Habana". Disponible en https://fnff.es/ [Consulta: 1 de febrero de 2021].

Franco, F. 24 de julio de 1955a, "Discurso pronunciado en Burgos, durante el acto de inauguración del monumento al Cid Campeador". Disponible en https://fnff.es/ [Consulta: 1 de febrero de 2021].

Franco, F. 12 de octubre de 1955b, "Discurso pronunciado en Barcelona con motivo de agradecer por la Medalla de la Hispanidad otorgada a Carmen Polo y para conmemorar el Día de la Hispanidad". Disponible en https://fnff.es/ [Consulta: 3 de febrero de 2021].

Franco, F. 17 de julio de 1956, "Discurso pronunciado en Madrid ante el Consejo Nacional del Movimiento". Disponible en https://fnff.es/ [Consulta: 7 de febrero de 2021].

Franco, F. 2 de abril de 1959, "Discurso pronunciado, con motivo de la inauguración del Valle de los Caídos". Disponible en https://fnff.es/ [Consulta: 3 de febrero de 2021].

Franco, F. 29 de diciembre de 1960, "Mensaje de fin de año a todos los españoles, Emitido a través de Radio Nacional de España de Madrid". Disponible en https://fnff.es/ [Consulta: 3 de febrero de 2021].

Franco, F. 1 de octubre de 1961, "Discurso pronunciado desde el balcón del Ayuntamiento de Burgos, con motivo del XXV Aniversario de su Exaltación a la Jefatura del Estado". Disponible en https://fnff.es/ [Consulta: 3 de febrero de 2021].

Stroessner, A. 25 de mayo de 1954a, "El gobierno, una misión social trascendente. Discurso pronunciado al pueblo colorado en el Estadio Comuneros". Disponible en http://www.portalguarani.com/1759 alfredo stroessner matiauda.html [Consulta: 29 de enero de 2021].

Stroessner, A. 15 de agosto de 1954b, "Discurso pronunciado en el acto popular realizado en el estado del Club Cerro Porteño con motivo de la visita del Presidente de Argentina general Juan Domingo Perón". Disponible en http://www.portalguarani.com/1759 alfredo stroessner matiauda.html [Consulta: 29 de enero de 2021].

Stroessner, A. 1 de abril de 1961a, "Mensaje presidencial a la Honorable Cámara de Representantes". Disponible en http://www.portalguarani.com/1759 alfredo stroessner matiauda.html [Consulta: 25 de enero de 2021].

Stroessner, A. 1961b. "Discurso pronunciado en la inauguración del puente internacional sobre el río Paraná". Disponible en http://www.portalguarani.com/1759 alfredo stroessner matiauda.html [Consulta: 24 de enero de 2021].

Stroessner, A. 1977, Politica y estrategia de desarrollo, Instituto Colorado de Cultura, Asunción.

Stroessner, A. 22 de noviembre de 1987, "Discurso pronunciado ante la magna convención extraordinaria del Partido Colorado aceptando su postulación para el período presidencial 1988-1993”. Disponible en

http://www.portalguarani.com/1759 alfredo stroessner matiauda.html [Consulta: 22 de enero de 2021]. 


\section{BIBLIOGRAFÍA}

Alares López, G. 2017, “Sobre la cultura histórica del franquismo: historiadores, narrativas y Conmemoraciones" en Cabiers de Civilisation Espagnole Contemporaine, Vol. 18, pp. 1 a 9.

Alares López, G. 2020, “1939, el año de los fascismos" en Alquézar Penón, J. Zubero, L. \& Alares López, G. 1919-1929-1939. Crisis de la democracia, CELAN, Andorra, pp. 47 a 65.

Álvarez Junco, J. \& de la Fuente, G. 2017, El relato nacional. Historia de la historia de España, Penguin Random House Grupo Editorial, Barcelona.

Fuentes Armadans, C. 2016, La maldición del legionario. Cómo se construyó un estigma político autoritario en el Paraguay, Editorial Tiempo de Historia, Asunción.

Benítez, L. 1963, Manual de historia paraguaya: para del primer curso del ciclo básico, El Arte, Asunción.

Bourdieu, P. 2001, Las estructuras sociales de la economía, Manantial, Buenos Aires.

Bourdieu, P. 2002, Campo de poder, campo intelectual. Itinerario de un concepto, Buenos Aires.

Brezzo, L. 2014, "El historiador y el general: imposiciones y disensos en torno a la interpretación pública de la historia en Paraguay" en Nuevo Mundo Mundos Nuevos. Disponible https://journals.openedition.org/nuevomund o/67479 [Consulta: 17 de febrero 2021].

Brezzo, L. 2016, "Institucionalizar la escritura del pasado. La Academia Paraguaya de la Historia (1937-1965)" en Anuario de Estudios Americanos, Vol. 73, Núm. 1, pp. 291 a 317.

Brezzo, L. \& Scavone Yegros, R. 2017, "Edición e introducción" en Seiferheld, A. Testimonios para la historia del Paraguay en el siglo XX. Tomo I, Servilibro, Asunción, pp. 9 a 34.

Capdevila, L. 2010, Una guerra total: Paraguay, 1864-1870. Ensayo de tiempo presente, Centro de Estudios Antropológicos de la Universidad Católica.

Capdevila, L. 2008, "Para una historia del tiempo presente paraguayo. Del pasado/presente entre dictadura y democracia: los historiadores bajo la dictadura" en Res Gesta, Núm. 46, pp. 37 a 58.

Duplá, A. 2002, "El franquismo y el mundo antiguo. Una revisión historiográfica" en Forcadell Álvarez, C. \& Peiró, I. (Coords.)
Lecturas de la historia: nueve reflexiones sobre historia de la historiografia, Institución Fernando el Católico, Zaragoza, pp. 167 a 190.

Eiroa San Francisco, M. 2012, "Palabra de Franco. Lenguaje político e ideología en los textos doctrinales" en Navajas Zubeldía, C. \& Iturriaga, D. (Eds.) Coetánea. Actas del III Congreso Internacional de Historia de Nuestro Tiempo, Universidad de La Rioja, Logroño, pp. 71 a 88.

Figallo, B. 2018, "Estrategias diplomáticas de la España del desarrollo en Sudamérica. Los escritores Giménez Caballero y Alfaro en Paraguay y Argentina" en Claves. Revista de Historia, Vol. 4, Núm. 7, pp. 89 a 128.

Fontana, J. 1999, "Manuel Tuñón de Lara y la tradición democrática española. Prólogo" en de la Granja, J. L., Reig Tapia, A. \& Millares R. (Eds.) Tuñón de Lara y la bistoriografía española, Siglo XXI, Madrid.

González Cuevas, P. 1989, "Salvador de Madariaga, pensador político" en Revista de Estudios Políticos (Nueva Época), Núm. 66, pp. 145 a 181.

González, J. N. 1935, El Paraguay eterno, Editorial Guarania, Asunción.

Irala Burgos, A. 2003, "El Paraguay mestizo y sus valores para el siglo XXI" en Estudios Paraguayos, Vol. XX - XXI, Núm. 1 - 2, pp. 209 a 221.

Merino, J. 2020, "Los hechos son sagrados", en El Correo de España. Disponible en https://elcorreodeespana.com/opinion/5692 66102/Los-hechos-son-sagrados-Por-Julio-

Merino.html [Consulta: 15 de diciembre de 2020].

Moradielos, E. 2018, Franco. Anatomía de un dictador, Turner, Madrid.

Orella, J. L. 1997, "La raíz canovista del nacionalcatolicismo de Franco" en Letras de Deusto, Vol. 77, Núm. 27, pp. 145 a 167.

Palacios, J. \& Payne, S. 2008, Franco, mi padre. Testimonio de Carmen Franco, bija del Caudillo, La Esfera de los Libros, Madrid.

Paredes, R. 2011, Stroessner y el stronismo, Servilibro, Asunción.

Pasamar, G. 2002, "La profesión de historiador en la España franquista" en Forcadell Álvarez, C. \& Peiró, I., Lecturas de la historia: nueve reflexiones sobre historia de la bistoriografía, Institución Fernando el Católico, Madrid, pp. 151 a 166. 
Pasamar, G. \& Peiró, I. 2002, Diccionario Akal de historiadores españoles contemporáneos, Akal, Madrid.

Pastor Martínez, M. 16 de febrero 2017, “Autoritarismo y totalitarismo", en La Crítica. El periódico independiente.

Peiró, I. 2013, Historiadores en España. Historia de la Historia y memoria de la profesión, Prensas de la Universidad de Zaragoza, Zaragoza.

Pérez Moreno, S. \& Meo, C. 1980, Stroessner, Edición Latinoamericana, Asunción.

Sánchez Illán, J. C. \& Lumbreras Martínez, D. 2016, "Francisco Franco, articulista de incógnito (1945-1960)", en Historia y Comunicación Social, 21, 1, pp. 39 a 74.

Soler, L. 2007, “Claves históricas del régimen político en Paraguay. López y Stroessner" en Diálogos, Vol. 11, Núm. 1 - 2, pp. 19 a 54.

Suevos, J. 17 de julio de 1973, "Franco recibió al presidente del Paraguay en el aeropuerto de Barajas", en $A B C$.

Velázquez Seiferheld, D. 2018, "Autoritarismo, nacionalismo y militarismo en la educación paraguaya (1936 - 1989)" en Diálogos, Vol. 22, Núm. 3, pp. 4 a 19. 